\title{
38. SEISMIC RESPONSE OF DETAILED STRUCTURE IN DEEP SEA DRILLING PROJECT HOLE 504B: SYNTHETIC SEISMOGRAMS IN THE DOMAIN OF INTERCEPT TIME AND RAY PARAMETER
}

\author{
John C. Mutter and Robin L. Newmark, Lamont-Doherty Geological Observatory and Department of Geological \\ Sciences, Columbia University ${ }^{2}$
}

\begin{abstract}
Synthetic seismograms in the domain of intercept time $(\tau)$ and horizontal ray parameter $(p)$ were computed for DSDP Hole 504B by using the detailed profiles of compressional-wave velocity, shear-wave velocity, and density made available by downhole logging. One hundred layers $10 \mathrm{~m}$ thick were defined for oceanic Layer 2 and used to compute seismic response to an idealized impulsive source with full-wave elastic synthetics. Layer $2 \mathrm{~A}$ showed large velocity variations, but its structure could not be interpreted. Relatively thin low-velocity zones in Layer 2B could easily be recognized by a discontinuity in the primary branch of postcritical energy in the $\tau$ - $p$ domain. Inversion of the synthetic seismogram using the $\tau$-sum method revealed many of the detailed variations indicated by the well logs. This result suggests that high-quality seismic data could be inverted to yield a much more detailed picture of portions of Layer 2 than is commonly thought possible.
\end{abstract}

\section{INTRODUCTION}

The most detailed knowledge of oceanic crust currently available comes from the study of ophiolites (which may represent oceanic crust emplaced on land by tectonism) and the material recovered by dredge hauls and deepocean drilling. These studies clearly demonstrate that significant geologic variations occur at spatial scales, both vertical and horizontal, that are far finer than the resolution capability of current marine seismic methods. These seismic methods provide a relatively coarse measure of the crust's bulk properties; they define a structure comprising, at most, 15 or so layers and resolve horizontal variations on scales no better than a few tens of kilometers. This difference in observational scales is an important limitation on the extrapolation of geologic data for regional studies.

Seismic data are commonly used to infer velocity profiles for the crust. Carefully constructed experiments in which digitally recorded data and computer-aided interpretation techniques are used provide velocity profiles consisting of up to a dozen or so layers with either uniform velocities or linear gradients. These seismically derived models are probably an order of magnitude poorer in resolution than geologic models of the oceanic crust. One reason for this limited resolution is the source spectrum of commonly used seismic energy sources. Most sources that are energetic enough to penetrate the crust have center frequencies around $10 \mathrm{~Hz}$ or less, and little useful energy above $20 \mathrm{~Hz}$. If one-quarter wavelength is considered the limit of resolution, this source spectrum provides the fundamental constraint on our observing

\footnotetext{
1 Leinen, M., Rea, D. K., et al., Init. Repts. DSDP, 92: Washington (U.S. Govt. Printing Office). Lamont-Doherty Geological Observatory Contribution No. 3953.

2 Addresses: (Mutter) Lamont-Doherty Geological Observatory and Department of Geological Sciences, Columbia University, Palisades, NY 10964; (Newmark, present address) Lawrence Livermore National Laboratory, Livermore, CA 94550.
}

power, limiting spatial resolution to perhaps $30 \mathrm{~m}$ in the upper crust and $200 \mathrm{~m}$ in the lower crust (e.g., Sheriff, 1977).

The limits of the resolving power of conventional seismic data are, however, seldom examined. It is generally assumed that even the most finely resolved seismic measurements lack sufficient resolution to be directly matched to geologic observations.

Physical property measurements from sonic logging in DSDP Hole 504B, south of the Costa Rica Rift (Fig. 1), provided detailed measurements of sonic velocity (compressional and shear wave) and density for the upper $1000 \mathrm{~m}$ of oceanic crust (Fig. 2). After resampling these data to form layers $10 \mathrm{~m}$ thick, we constructed synthetic seismograms by using the standard Fuchs-Müller reflectivity method as modified by Wenzel et al. (1982). Seismograms were constructed in the $X-T$ (i.e., offset-traveltime) and $\tau-p$ plane and examined for evidence of the narrow (less than 50-m) low-velocity zones that were revealed by the sonic logging. We concentrated most on $\tau-$ $p$ synthetics because the effects of low-velocity intervals are more easily identified in the $\tau-p$ domain.

\section{GEOLOGY OF THE OCEANIC CRUST AT HOLE 504B}

Hole 504B is on the Nazca Plate about $200 \mathrm{~km}$ south of the east-west-trending Costa Rica Rift. During Legs 69,70 , and 83 , the hole was drilled to a total depth of $1350 \mathrm{~m}$ below sea floor (BSF), $1075.5 \mathrm{~m}$ of which penetrate oceanic Layer 2 (Fig. 2). At the completion of drilling, downhole geophysical logging was undertaken, including multichannel sonic velocity logging (Anderson et al., 1982, 1985) and borehole televiewer logging (Newmark et al., 1985). The borehole televiewer is a logging tool that contains a rotating piezoelectric transducer that emits and receives ultrasonic pulses at a rapid rate while it is being pulled up the hole. The amplitude of the reflected pulses, which can be plotted as a function of 


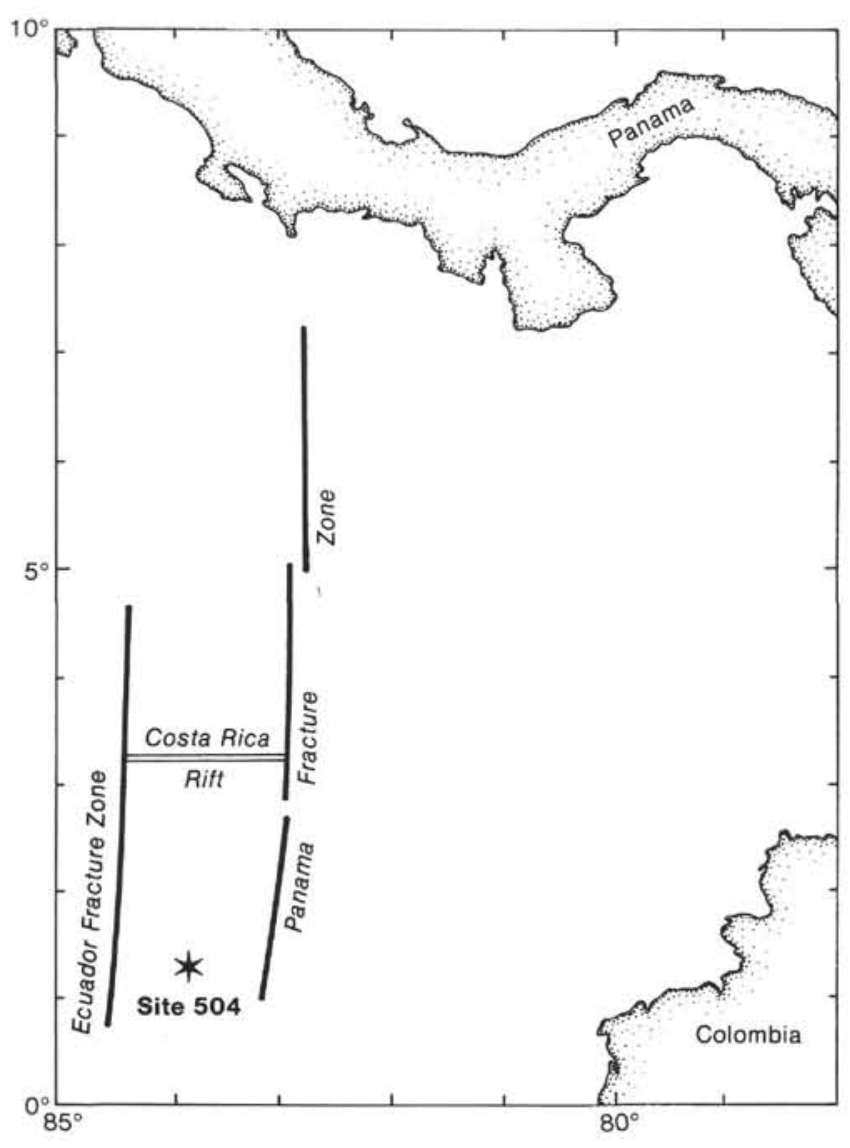

Figure 1. Location of Site 504 in the Panama Basin.

beam azimuth and vertical position in the hole, gives a measure of wellbore reflectivity. Logging of this type reveals structural features of the wellbore. Hard, solid rock, such as that found in pillow basalts and massive flows, produces high-amplitude reflectance; fractures and voids or soft material produces low-amplitude reflectance. The borehole televiewer images provide the structural information necessary to correlate and interpret the various geophysical logs with respect to the recovered core. The ability to make this correlation is particularly important when core recovery is poor, as it was during Leg 83. A detailed description of the lithostratigraphic structure of the hole as revealed by a comparison of the borehole televiewer imagery and the recovered core can be found in Newmark et al. (1985), of which the following is a summary.

The sediment section consists primarily of siliceous nannofossil oozes and chalks. The lower $30 \mathrm{~m}$ of the sediment section are composed of siliceous limestones and cherty layers (Cann, Langseth, Honnorez, Von Herzen, White, et al., 1983). The upper $50 \mathrm{~m}$ of basalt are composed mostly of thick flow units with numerous large fractures. (The fracturing throughout the hole is predominantly subhorizontal.) This upper basalt layer correlates with a shallow high-velocity zone in the sonic logs. Directly below this lies a 20 -m-thick zone of anomalous low reflectance that shows extensive large-scale fracturing, brecciation, and a large percentage of void space; this zone corresponds to the first low-velocity zone in the sonic logs (LVZ 1). This thin zone corresponds to the region of highest apparent bulk porosity in the hole (13 to $14 \%$; Becker et al., 1982). The next $30 \mathrm{~m}$ are mainly composed of thin flows and pillows; the average pillow size and flow thickness decrease with depth. These uppermost $100 \mathrm{~m}$ are part of seismic Layer 2A (Newmark et al., 1985).

The next $550 \mathrm{~m}$ are composed mainly of small-diameter $(<10-\mathrm{cm})$ pillow basalts and thin $(<20-\mathrm{cm})$ flows and breccias. Fracturing is pervasive. This part of the section contains an abundance of hydrated minerals and alteration products (Anderson et al., 1982) and is interpreted as seismic Layer 2B. There are two large massive flow units, one from 3986.5 to $4001.5 \mathrm{~m}$ below sea level (bsl) and one from 4034.5 to $4044.5 \mathrm{~m}$ bsl (526.5 to $541.5 \mathrm{~m}$ BSF and 574.5 to $584.5 \mathrm{~m}$ BSF). There are also a few smaller massive flow units such as those between 4124.5 and $4128.5 \mathrm{~m}$ bsl, 4134.5 and $4144.5 \mathrm{~m}$ bsl, 4174.5 and $4180.5 \mathrm{~m}$ bsl, and 4194.5 and $4198.5 \mathrm{~m}$ bsl $(664.5$ and $668.5,674.5$ and $684.5,714.5$ and 720.5 , and 734.5 and $738.5 \mathrm{~m} \mathrm{BSF}$ ). All these intervals (massive flow units) roughly correspond to intervals of relatively high sonic velocity in the logs. The borehole televiewer images also show several zones of anomalously low reflectance, which indicates extensive brecciation and alteration. These zones are from 3956.5 to $3966.5 \mathrm{~m}$ bsl, 4066.5 to $4080.5 \mathrm{~m} \mathrm{bsl}$, 4144.5 to $4193.5 \mathrm{~m} \mathrm{bsl}$, and 4240.5 to $4306.5 \mathrm{~m}$ bsl ( 496.5 to $506.5,606.5$ to $651.5,684.5$ to 733.5 , and 780.5 to $846.5 \mathrm{~m} \mathrm{BSF}$ ). These zones correspond roughly to low-velocity zones in the sonic logs. The correlation is especially pronounced for the two intervals from about 4040 to $4090 \mathrm{~m}$ bsl and from 4230 to $4290 \mathrm{~m}$ bsl (580 to 630 and 770 to $830 \mathrm{~m} \mathrm{BSF}$; LVZ 2 and LVZ 3); in these intervals both the compressional- and the shear-wave velocities decrease. In two other intervals (from 3940 to $3970 \mathrm{~m}$ bsl and from 4130 to $4170 \mathrm{~m}$ bsl; 480 to 510 and 670 to $710 \mathrm{~m} \mathrm{BSF}$ ), the compressional velocity decreases whereas the shear velocity shows little or no change. The difference between the sets of intervals may reflect the difference between rocks with open (void) spaces, which greatly reduce both the compressional and shear velocities, and rocks with spaces sealed with alteration products, which reduce the compressional velocity more than the shear velocity. Although Layer $2 \mathrm{~B}$ is the most extensively altered section of the hole, some intervals contain more void space than others. The borehole images show that the interval from 4233.5 to $4306.5 \mathrm{~m}$ bsl ( 773.5 to $846.5 \mathrm{~m} \mathrm{BSF}$ ), for example, for which core recovery was especially low, had a larger percentage of void space than the interval from 4156.5 to $4196.5 \mathrm{~m}$ bsl ( 696.5 to $736.5 \mathrm{~m}$ BSF).

The lower $350 \mathrm{~m}$ of the hole penetrated primarily sheeted dikes of seismic Layer 2C. At depths from 4376.5 to $4446.5 \mathrm{~m}$ bsl ( 916.5 to $986.5 \mathrm{~m} \mathrm{BSF}$ ), the borehole is generally reflective, and it is solid and massive in appearance. The overall level of reflectance in the borehole televiewer images drops a bit below $4446.5 \mathrm{~m}$ bsl $(986.5 \mathrm{~m}$ BSF), but reflectance then gradually increases again to the bottom of the hole. Although the lower $350 \mathrm{~m}$ is fractured, this lower section of the hole is less heavily fractured than the overlying material. There is a rough 


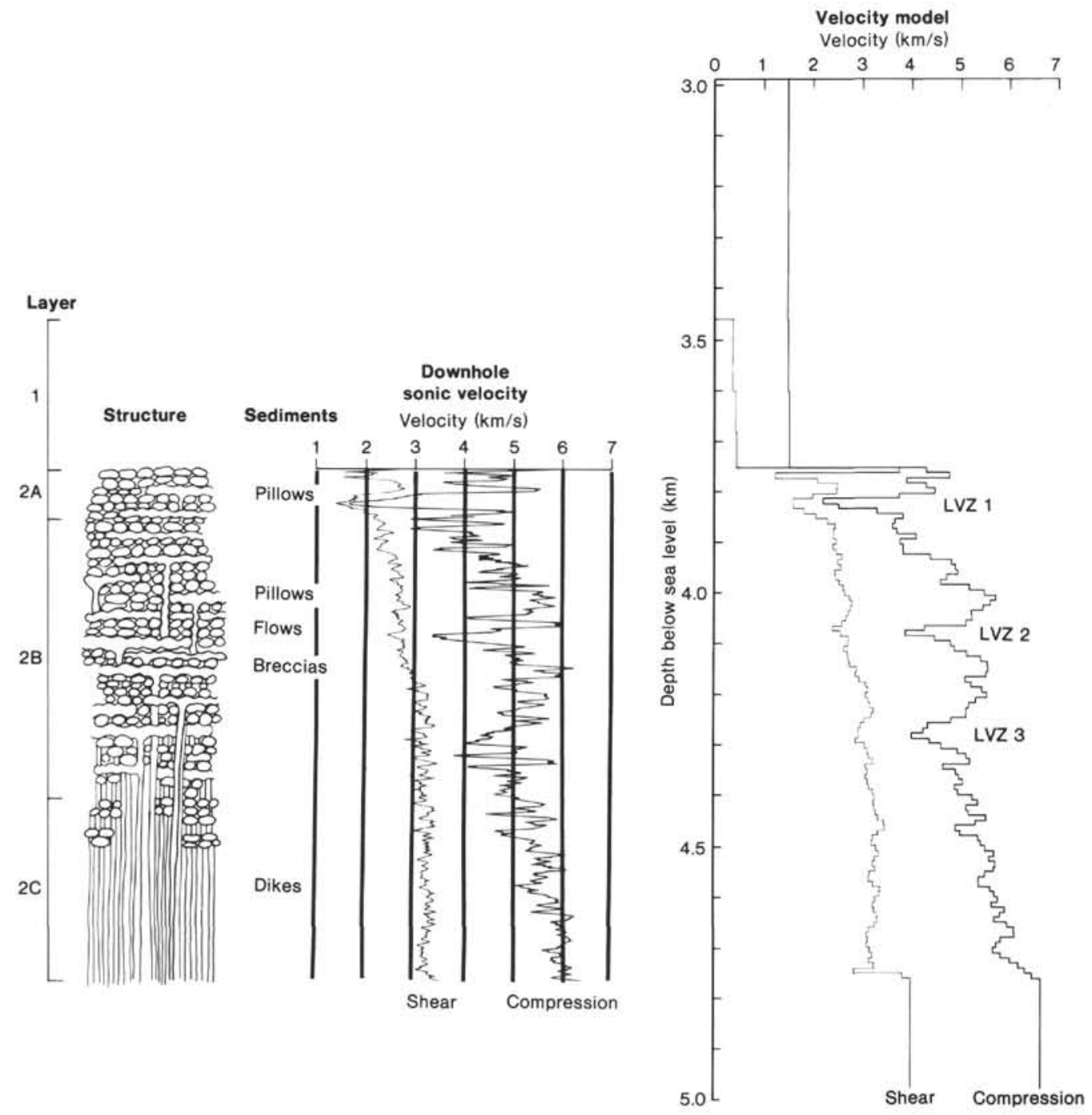

Figure 2. Downhole sonic velocities in the upper $1 \mathrm{~km}$ of basement in DSDP Hole 504B. On the left is a schematic section indicating the dominant lithologic units. Designation of seismic Layers 1, 2A, 2B, and 2C is from Newmark et al. (1985). In the center are 10-m running average of the logged downhole shear- and compressional-wave velocities. On the right is a simplified velocity model derived from the sonic logs; the sediment column is divided into three layers and the basement is represented by 100 layers $10 \mathrm{~m}$ thick. (After Newmark et al., 1985.)

correlation between the variations in the compressionalwave velocity and the overall integrity of the wellbore as revealed by the borehole televiewer images. For example, from about 4646.5 to $4676.5 \mathrm{~m}$ bsl (1186.5 to $1216.5 \mathrm{~m}$ BSF), the wellbore is relatively smooth and massive, and the compressional velocity is relatively high. Below this there is an interval $\approx 15 \mathrm{~m}$ thick of low reflectivity, brecciation, and large fractures that correlates to a zone of lower compressional velocity in the sonic logs (Fig. 2). From about $4496.5 \mathrm{~m}$ bsl (1036.5 m BSF) to the bottom of the hole, the wallrock appears massive and relatively unfractured; compressional velocity increases over this interval.

\section{CONSTRUCTING THE SYNTHETIC SEISMOGRAMS}

The parameters used to define the crustal model are compressional-wave velocity, shear-wave velocity, and den- sity. The velocities were obtained from a Schlumberger four-channel sonic tool, which has a broadband source with a center peak of $\approx 2$ to $20 \mathrm{kHz}$. Compressional velocities were measured by first running the log in a firstarrival mode; then full waveform digitization of the four available channels was carried out. In the basalt section, shear-wave data were obtained by setting a moving-gate window to exclude the earlier-arriving compressional signal (Anderson et al., 1985). Densities were obtained from a standard gamma ray log. In the sediment section, shear velocities and densities were obtained from sample measurements. The three logged parameters were measured almost continuously down the hole. To obtain a model structure from which the synthetic seismic response could be computed, we resampled these parameters by using a 10 -m-wide moving window in which the logged values were averaged. The resulting model structure contains a total of 104 layers, including the water column, 3 sediment layers, and 10010 -m intervals in the basaltic crust. 
The fracture and alteration changes visible in the borehole televiewer logs generally correspond to changes in the seismic and sonic velocities at Site 504 (see Stephen and Harding, 1983; Anderson et al., 1985; and Newmark et al., 1985). This correspondence suggests that the sonic and seismic velocity measurements are primarily influenced by macrofractures instead of microfractures. The similarity of velocities determined from the very different wavelengths of seismic and sonic energy transmission led Moos and Zoback (1983) to a similar conclusion about wells drilled through crystalline basement on land. This study attempts to test the sensitivity of a seismic experiment to the presence of zones of macrofractures, which are known to influence the measurement of sonic velocity during well logging.

Synthetic seismograms were computed for the model in both the $X-T$ and the $\tau-p$ domain by using the model of Wenzel et al. (1982). In this procedure, which is based on the standard Fuchs-Muller reflectivity method, the seismic response is evaluated for equally spaced ray parameters and frequencies. The response in the $\tau-p$ plane is then obtained by an inverse Fourier transform over frequency; a further integration over ray parameter yields the $X-T$ synthetic (Fig. 3 ). We performed most of our analysis by generating complete synthetics (that is, full elastic models with homogeneous layers assumed and all multiples included) in the $\tau-p$ domain using ray parameter increments of 1 and $3 \mathrm{~ms} / \mathrm{km}$. Analysis in this domain is easier and has a number of advantages for those studying the seismograms:
1. $\tau-p$ synthetics can be computed more rapidly than $X-T$ synthetics because computing the latter requires a further integration over several hundred discrete values of $p$.

2 . In the $\tau-p$ plane, the locus of arrivals used in many traveltime inversion schemes is represented by a singlevalued, monotonically increasing function of $\tau$ and $p$ that can usually be easily identified.

3. Multiples are easy to recognize by their intercept time periodicity.

4. Shear arrivals are clearly separated from compressional arrivals, forming a distinct branch of postcritical energy at larger ray parameters.

5. The effects of low-velocity intervals within a structure are easy to recognize as distinct offsets in the branch defining the postcritical energy.

Of these properties, the last is particularly valuable in the present study, because the sonic velocity measurements (Fig. 2) reveal three narrow low-velocity intervals, and one objective of our study was to determine whether the seismic response of such small features could be recognized in the synthetics. Structural details are not easy to identify in the $X-T$ synthetic (Fig. 3).

To simulate the bandwidth of an air gun sound source, we computed the synthetics with frequencies ranging from 0 to $125 \mathrm{~Hz}$, which were then passed through a broadband filter ranging from 5 to $50 \mathrm{~Hz}$, with flat response from about 10 to $30 \mathrm{~Hz}$. The synthetics are, however, noise free; we did not attempt to model bubble pulse reverberations or other noise in realistic seismic sources.

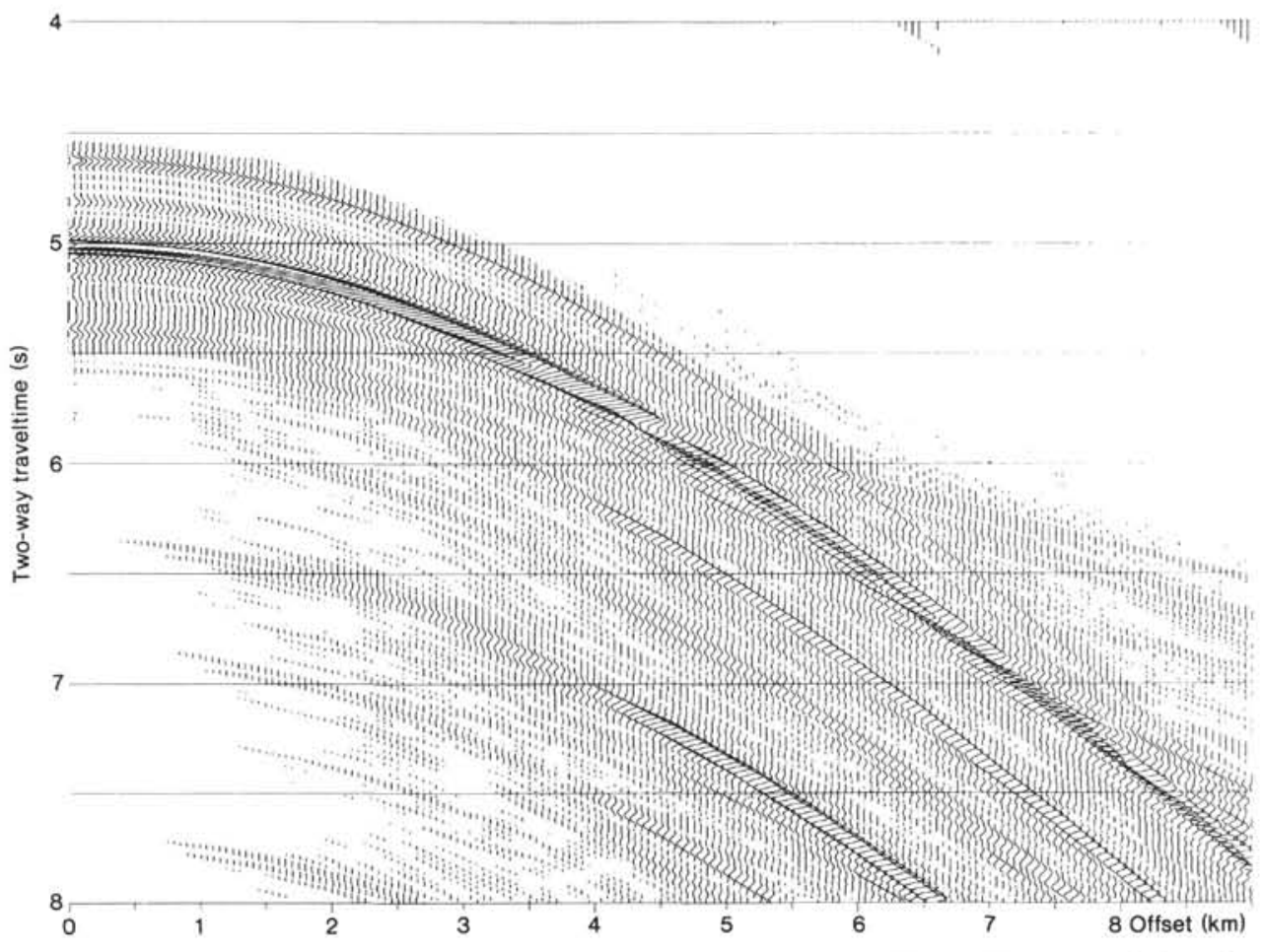

Figure 3. Synthetic seismogram in the $X-T$ domain computed using the 104-layer velocity model shown in Figure 2. 


\section{SYNTHETIC SEISMOGRAMS IN THE $\boldsymbol{\tau}-\boldsymbol{p}$ DOMAIN}

Figure 4 shows the 104-layer model structure (compressional-wave velocities only) and the $\tau-p$ synthetic seismogram derived therefrom. The seismogram reflects full elastic response (all multiples are included) and uses compressional-wave velocity, shear-wave velocity, and density for each layer. It is displayed at a slowness increment of $3 \mathrm{~ms} / \mathrm{km}$.

The primary branch (Phinney et al.'s, 1981, terminology) of postcritical shear and compressional arrivals is clearly defined. Both originate at a strong reflected arrival from the sediment/basement interface that has a vertical incidence reflection time (intercept time for $p=$ 0 ) of a little more than $5.0 \mathrm{~s}$. The commencement (i.e., largest $p$ for smallest $\tau$ ) of the observed postcritical branch for $p$ phases occurs on the sediment/basement reflector at a slowness of about $264 \mathrm{~ms} / \mathrm{km}$, which corresponds to a velocity of $3.8 \mathrm{~km} / \mathrm{s}$. This velocity is much lower than the peak velocity shown in the model structure at the left for the crust that lies above the low-velocity zone marked LVZ 1. We observe no distinct response in the synthetic to either the uppermost low-velocity zone (LVZ 1) or the higher-velocity crust above it. That is, the pillow basalts of Layer $2 \mathrm{~A}$ do not generate recognizable features in the primary branch $\tau-p$ synthetic.

The effect of there being a low-velocity zone at such a shallow depth beneath the sediment/basement interface is to generate a strong complex reflection at that interface. Interference effects (which may be defined as the sum of the arrivals that undergo a $180^{\circ}$ phase shift; i.e., reflections from negative velocity contrasts) lead to the generation of a very complex waveform. Interference effects can be recognized in Figure 4 where the major negative velocity contrast occurs (at LVZ 1 in Layer 2A). Similar effects have been found by exploration seismologists in regions where oil/water/gas/rock interfaces produce alternating positive and negative contrasts in compressional velocity (Dedman et al., 1975). The nature of the interference depends on the relative spacing of the positive or negative velocity contrasts.

The velocity gradient beneath LVZ 1 gives rise to the continuous band of energy in $\tau-p$ between 264 and 198 $\mathrm{ms} / \mathrm{km}$. At $198 \mathrm{~ms} / \mathrm{km}$ the primary branch becomes discontinuous, showing a small offset to larger intercept times. In a $\tau-p$ representation of seismic data, this feature can be interpreted as evidence of the presence of a low-velocity zone within an otherwise gradationally increasing velocity profile (see Aki and Richards, 1980, for a general discussion; and Phinney et al., 1981, for a discussion of slant-stack data).

Figure 5 illustrates the effect of a low-velocity zone on a simple, arbitrary earth model. The upper and lower velocity profiles are different only in that the fourth layer of the upper profile is divided into two layers in the lower profile, and the deeper of these two layers has a velocity inversion. The traveltimes of primary events are shown in the plots at the left. The upper plot, which reflects velocities that only increase with depth, exhibits a continuous band of postcritical arrivals (Stoffa et al., 1981; Diebold and Stoffa, 1981; Phinney et al., 1981;
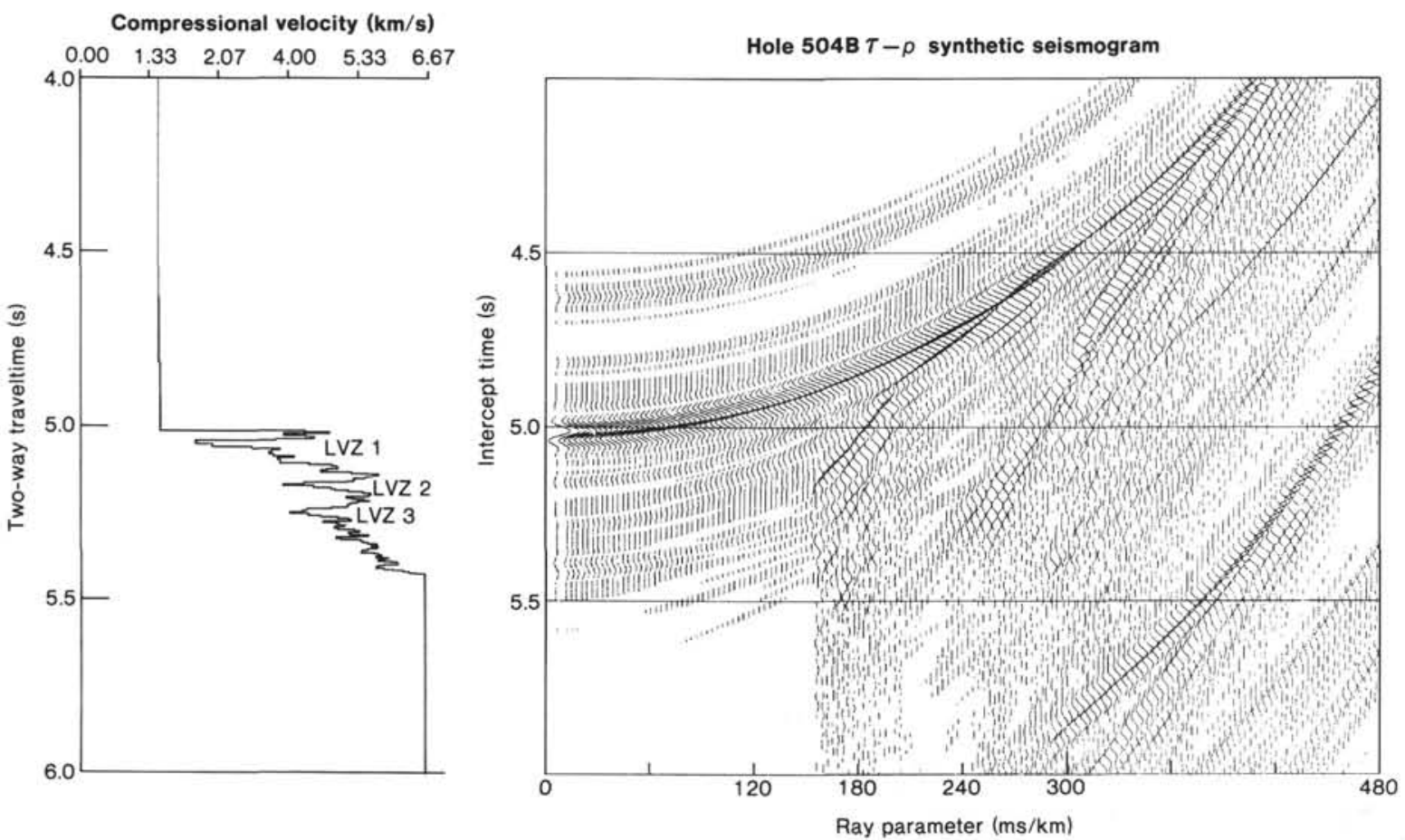

Figure 4. The 104-layer model structure derived from logging the basalts and sampling the sediments is shown on the left (compressional velocity structures only). At the right is the synthetic seismogram in the $\tau-p$ domain for a ray parameter increment of 3 $\mathrm{ms} / \mathrm{km}$ that was derived from the model structure. Shear velocity data and densities were used in the computation of the synthetic as described in the text. 


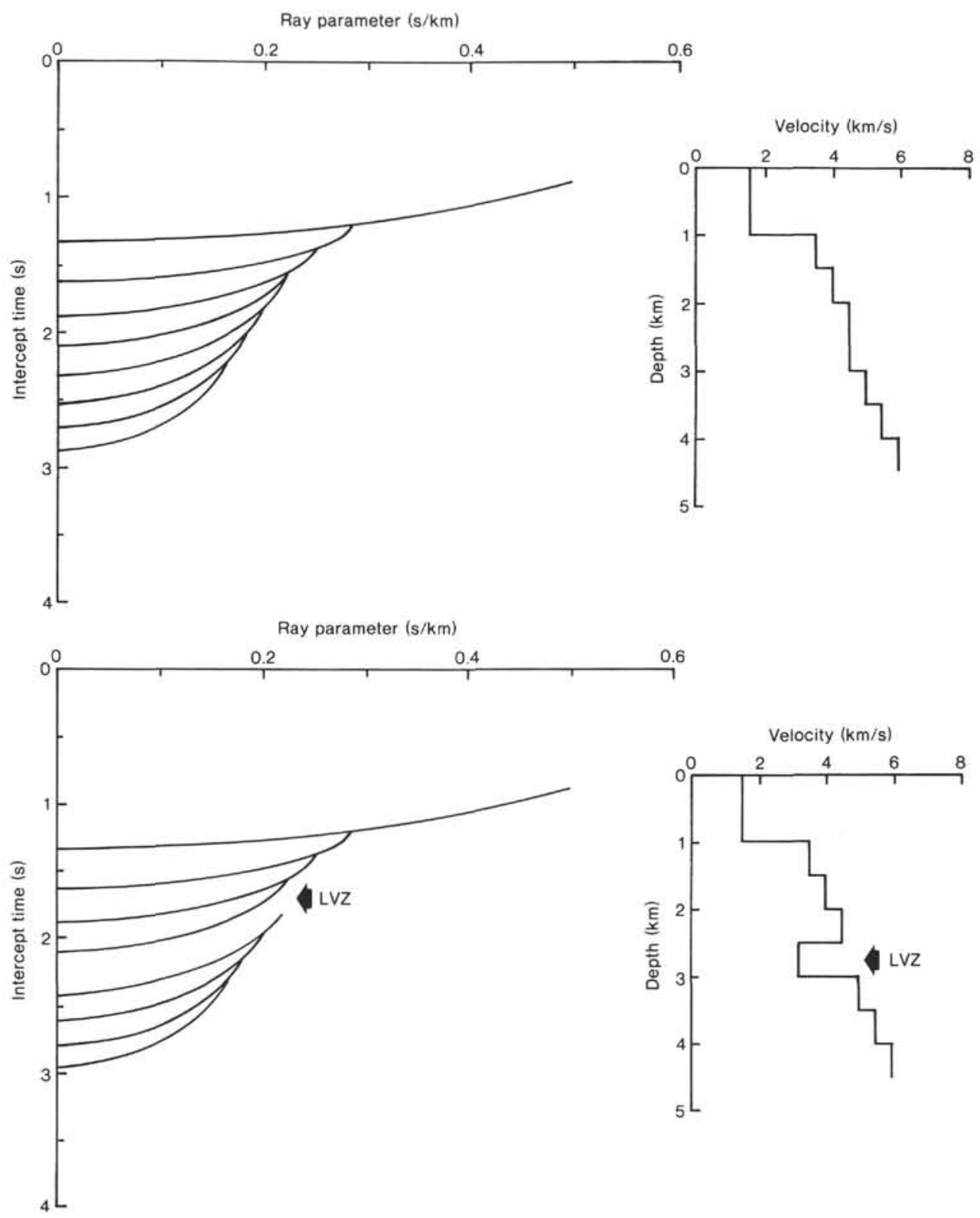

Figure 5. Ray tracing through simple structures to demonstrate the effect in the $\tau-p$ domain of a low-velocity interval. As described in the text, low-velocity intervals cause a discontinuity in the primary branch of postcritical arrivals.

McMechan and Ottolini, 1980). Each arrival reflected from the base of a uniform-velocity layer within the stack approximates a quarter-ellipse that meets a similar reflection from the overlying layer. The point at which the two quarter-ellipses meet is at the slowness appropriate to the lower layer, and physically represents the critically reflected ray in the upper layer. When the deeper layer has a lower velocity (greater slowness), rays entering the layer are turned downward, and so do not have turning points in the layer. No critically reflected ray can exist in the upper layer. The quarter-ellipses for reflections from the base of the LVZ terminate at the slowness of the overlying layer, giving rise to the discontinuity seen in the primary branch. This branch is continuous again below the LVZ, because rays that pass through it can turn in deeper layers.
The $\tau-p$ synthetic (Fig. 4) shows a small displacement at $p=198 \mathrm{~ms} / \mathrm{km}$ that could represent the effect of a low-velocity zone. We can trace the reflection from the base of LVZ 2 into the region of this displacement. The point of termination of the event cannot be recognized because of interference with other arrivals in the region of the discontinuity. Nevertheless, the synthetic seismogram in $\tau-p$ appears to show a recognizable response to the narrow low-velocity zone (LVZ 2) in Layer 2B of the upper oceanic crust.

A third low-velocity zone, LVZ 3, has a basal reflection that can be traced toward the region of discontinuity but is lost in interference effects near $p=186 \mathrm{~ms} /$ $\mathrm{km}$. The primary branch of energy in the $\tau-p$ synthetic is apparently continuous beneath (i.e., at greater intercept times than) the discontinuity from $p=198$ to $p=$ 
$153 \mathrm{~ms} / \mathrm{km}$. This is the velocity range, 5.05 to $6.5 \mathrm{~km} / \mathrm{s}$, that defines the gradient at the transition into the dike complex at the top of oceanic Layer 2C (Fig. 2).

The shear-wave energy in the $\tau-p$ synthetic exhibits a deflection in the primary branch at a slowness of about $300 \mathrm{~ms} / \mathrm{km}$, but it does not appear to be discontinuous. Low-velocity zones that correspond to those in the compressional-wave profile occur in the shear profile but are less distinct (Fig. 2). The feature at $4.1 \mathrm{~km}$ bsl in Figure 2 causes a velocity drop of $\leqq 10 \%$ in shear and $\geqq 30 \%$ in compressional arrivals. This comparatively indistinct response probably accounts for the lack of resolution of this feature in the shear branch of the $\tau-p$ synthetic.

Figure 6 shows a detail of the compressional branch of arrivals in a $\tau-p$ synthetic that is displayed for a ray parameter increment of $1 \mathrm{~ms} / \mathrm{km}$. All the features that were described with respect to the $p=3 \mathrm{~ms} / \mathrm{km}$ synthetic (Fig. 4) are more clearly resolved in this display. The displacement at about $p=198 \mathrm{~ms} / \mathrm{km}$ is quite distinct. At larger values of $p$ the postcritical energy appears to be concentrated into a branch that appears, visually, to be a single quarter-ellipse, suggesting that most of the energy is generated from a reflection from a single interface. The primary branch at values of $p$ less than the $p$ of the discontinuity is not a simple quarter-ellipse. It appears to be nearly linear, although there is a deflec- tion at about $p=175 \mathrm{~ms} / \mathrm{km}$. Specifically, the synthetic shows a range of convex and concave curvatures that can be interpreted as the combined effects of postcritical reflections from simple interfaces and diving rays that pass through layers with gradational velocities. All these reflections interfere with each other when the individual branches merge to form the primary branch in the $\tau-p$ seismogram.

As noted above, the $\tau-p$ synthetic is generated under idealized conditions and involves making a number of assumptions; as a result, the seismograms are also unrealistically clear. The less-than-ideal conditions of real seismic experiments lead to seismograms that are more difficult to interpret in detail. Much of the fine-scale structure seen in the $\tau-p$ synthetic would be smoothed out in real data by the mapping from the observations in $X-T$ space, and such detail as remained would exist in a background of random and systematic noise. However, modern seismic refraction experiments such as the twoship expanded spread profile (ESP; Stoffa and Buhl, 1979), which acquire data at a high spatial density by using multichannel recording, are yielding data with very high signal-to-noise ratio. Automated, computer-based techniques for mapping seismic data into the $\tau-p$ domain (Stoffa et al., 1981) preserve much of the detailed behavior of the seismograms. A feature such as the dis-

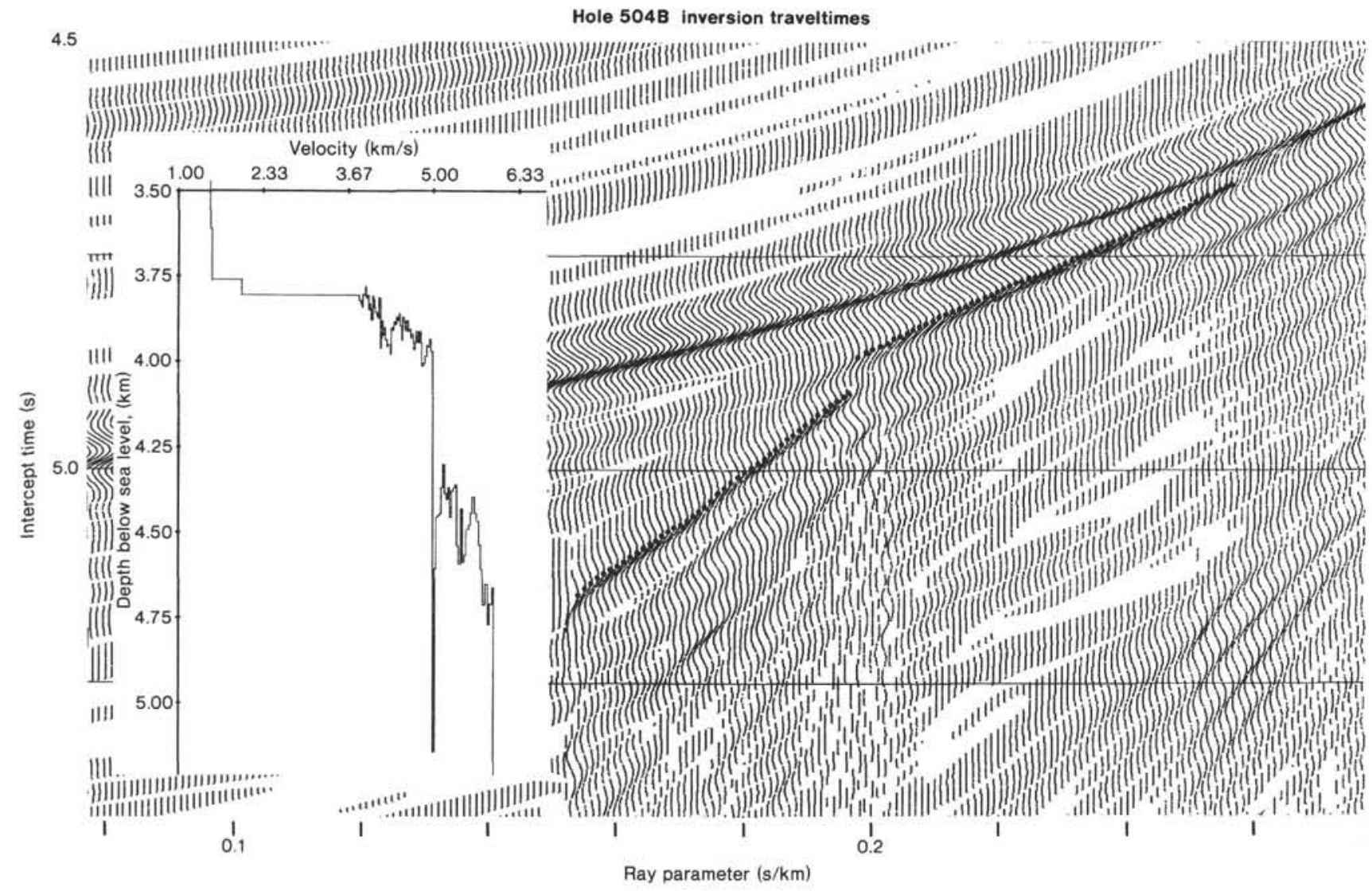

Figure 6. A detail of the $\tau-p$ synthetic (ray parameter increment of $1 \mathrm{~ms} / \mathrm{km}$ ). The insert shows a first-pass inversion structure derived from a $\tau$ sum inversion of $\tau, p$ data picked from the synthetic. The small dots on the synthetic are the $\tau, p$ points used in the inversion and were picked by hand to coincide with the maximum-amplitude data in the primary branch. 
continuity at $p=198 \mathrm{~ms} / \mathrm{km}$, which appears to be the response to LVZ 2, might well be preserved in real data of this type.

\section{TRAVELTIME INVERSION OF THE $\tau-p$ SYNTHETIC}

To derive a velocity-depth profile from $\tau-p$ data, a set of discrete $\tau, p$ pairs must be obtained from the seismogram and used in a traveltime inversion scheme like the Herglotz-Wiechert method or the $\tau$-sum scheme of Diebold and Stoffa (1981). To see how well we could recover the known velocity-depth profile in Hole 504B from its $\tau-p$ synthetic, we picked $\tau, p$ pairs along the primary branch of the synthetic and derived a $\tau$-sum inversion. The maximum amplitude was picked for values of $p$ from 154 to $260 \mathrm{~ms} / \mathrm{km}$ (shown as dots in Fig. 6). Sediment velocities were taken from the sample measurements and used in the upper part of the velocity-depth profile; the remainder were derived from the $\tau$-sum inversion.

The profile derived is quite ragged in detail, although overall it is a fairly good approximation of the logged profile. A major excursion occurs at a velocity of about $5 \mathrm{~km} / \mathrm{s}$ that results from the discontinuity in the $\tau-p$ data at $p=198 \mathrm{~ms} / \mathrm{km}$ (i.e., $5.05 \mathrm{~km} / \mathrm{s}$ ). The $\tau$-sum inversion assumes that each discrete $\tau, p$ point results from the critically reflected ray in a layer. This assumption is equivalent to assuming that a single, complete quarterellipse from a single uniform layer exists between any two $\tau, p$ pairs. Low-velocity regions cannot be directly inverted for by the $\tau$-sum method. Where a large step in the $\tau-p$ trajectory is present (a large change in $\tau$ for a small change in $p$ ), a thick layer will be computed. $\tau, p$ pairs beneath the step with small $\tau$ and $p$ increments will yield negative layer thicknesses. One way to visualize a negative layer thickness is to recognize that a quarter-ellipse fitted to a pair of $\tau, p$ points with a large change in $\tau$ will have a large value of $\tau$ at $p=0$; that is, the normal incidence traveltime is large. $\tau, p$ pairs beneath with small changes in $\tau$ may have equivalent quarter-ellipses that lead to smaller values of $\tau$ at $p=0$, or normal incidence; and these will result in layers of negative thickness. Hence, one way to interpret the downward excursions in the velocity profile in Figure 6 is to attribute them to the negative-thickness layers that will result when the $\tau$-sum inversion procedure encounters the $\tau-p$ discontinuity that results from a low-velocity zone.

In practice one might not make such an interpretation. The primary branch of $\tau-p$ data is seldom completely defined; even in theory it cannot be, unless the data are recorded to infinite range. A first-pass inversion like that in Figure 6 would be simplified by lopping off the negative-thickness excursions on the assumption that limitations in the data caused the $\tau-p$ data to be discontinuous. However, an interpretation of the discontinuities as the expression of low-velocity intervals is equally valid, although perhaps not the interpretation that would be made unless the interpreter knew in advance that lowvelocity zones might occur in the structure under investigation. The logging and sampling in Hole 504B show that low-velocity intervals in Layer 2 of the oceanic crust do not result from major petrologic variations or exceptional changes in structure downhole. Instead, crack density, crack geometry, intercrack passageways, water circulation, and hydrothermal mineralization interact in such a way as to produce major oscillations with increasing depth in the bulk properties of the rock in the upper part of the crust, oscillations reflected in the velocity structure. There is no reason to suppose that the low-velocity intervals at Hole 504B are unique to that site.

Figure 7 shows the velocity profile we derived from the first-pass $\tau$-sum inversion by assuming that the negative-thickness excursions result from the effects of lowvelocity zones. The profile includes only 15 layers, five of which exhibit velocity reversals. Our interpretation was also extensively guided by ray-trace fitting onto the $1 \mathrm{~ms} / \mathrm{km} \tau-p$ synthetic. Our approach was to take a trial structure by averaging through the first-pass $\tau$-sum inversion structure (in which low-velocity intervals were included, where they seemed appropriate) and then generating a ray-tracing of the primary arrivals for that structure that could be overlaid on the synthetic data. The structure was then iteratively modified until we judged that we had achieved the ray tracing that showed the best fit of the synthetic precritical reflections and had terminations in the regions where discontinuities in the primary branch of the synthetic were visible. The structure shown in Figure 6 is the result of numerous iterations, a number of which fit the synthetic almost as well. The choice of Figure 6 as the best fit was subjective.

As a guide to interpretation, we also generated a suite of synthetics in $\tau-p$ space from simplified structures. We computed a seismogram for a structure over $1000 \mathrm{~m}$ in depth that consisted of a simple linear velocity gradient except that it had three low-velocity zones; we then varied the thickness of the low-velocity zones until the structure appeared as a gradient with high-velocity excursions. This allowed us to judge the minimum width that a low-velocity region could have at a given depth in the gradient structure and be recognizable in the seismogram.

The arrows in the synthetic seismogram in Figure 7 indicate the reflector terminations caused by the five lowvelocity intervals. The ray-traced precritical reflections match the synthetic reflections particularly closely. The reflector terminations are more difficult to match accurately. As the figure shows, the traced reflections merge very closely and will interfere considerably in the region of the terminations, particularly those deeper in the section. We have included two low-velocity zones in Layer 2B (the upper two in the structure shown), because we observe clear reflections from the base of the upper feature, and from the interval between the two low-velocity zones, on the synthetic seismogram. Fitting those reflections accurately primarily guided the interpretation. These two low-velocity intervals appear to account for the discontinuity in the primary branch in the $\tau-p$ synthetic seismogram.

The three low-velocity zones beneath those in Layer 2B are less well resolved, and a satisfactory match to the synthetic could be made by excluding them. The simplified synthetics mentioned above also lead us to judge them to be of minimum detectable thickness. 


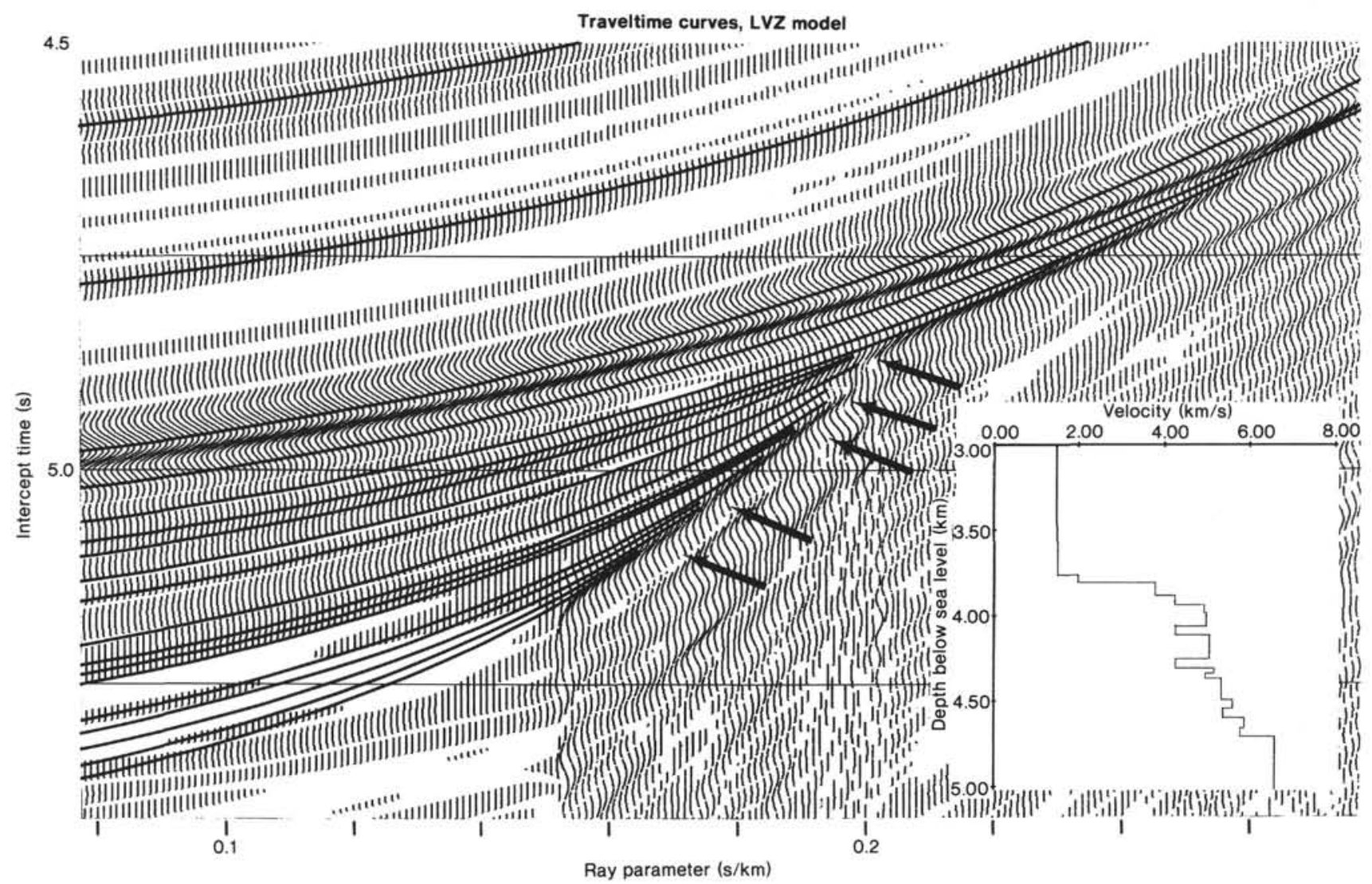

Figure 7. The insert shows a 15-layer crustal model that was derived by simplifying the first-pass $\tau$-sum inversion structure and inserting lowvelocity zones wherever the inversion exhibited significant excursions that could be interpreted as layers of negative thickness. The $\tau-p$ synthetic is shown with the ray-traced primary reflections superimposed. The arrows indicate the locations of reflector terminations caused by the low-velocity zones in the structure.

To check the validity of the result shown, we raytraced a structure that was the same as that in Figure 7 except that the low-velocity zones were removed. Although we could arrive at a reasonable fit for the region of the primary branch beneath the displacement at $198 \mathrm{~ms}$ / $\mathrm{km}$, we were unable to create a satisfactory match for either the precritical reflections or the reflector terminations in the vicinity of the $198-\mathrm{ms} / \mathrm{km}$ discontinuity.

The best-fit structure in Figure 7 is compared with the logged velocities in Figure 8. In general, the best-fit structure represents an average of the logged velocity profile. In Layer $2 \mathrm{~B}$, the averaging provides a rough approximation of structure. The structure in Layer $2 \mathrm{~A}$ is not resolved at all, however. The strong velocity reversal caused by the very high porosity due to fracturing and brecciation in the shallow crust beneath the uppermost flows (see Fig. 2 and previous discussion) occurs over such a small depth range that the high-velocity uppermost crust and low-velocity zone are averaged out. An analysis of the waveform of the reflected arrival from the sediment/basement interface might reveal the contrasts in velocity, but with a bandwidth restricted to 5 to $50 \mathrm{~Hz}$ it seems unlikely that the traveltime effects of these layers would be detected.

The Layer 2A structure averages to a stepwise increase in velocity over the upper $180 \mathrm{~m}$ or so of the basement and shows a velocity range from 2.0 to $5.0 \mathrm{~km} / \mathrm{s}$. This range, which is typical of that obtained for Layer $2 \mathrm{~A}$ from inversions of seismic refraction data, is often taken to be well represented by a simple, linear gradient. That interpretation, which is recognized as being a substantial simplification of the true structure, is a consequence of the constraints on the seismic experiments that can be performed at sea, the limitation of seismic bandwidths, and the limitations of interpretation techniques. One might expect large variations at shallow depths to be easier to recognize than those deeper in the section. Our analyses of the greatly idealized experiment that is represented by the synthetic data show that even under these conditions the major fluctuations in velocity in Layer $2 \mathrm{~A}$ cannot be resolved. One implication of this study is however that the structure of Layer $2 \mathrm{~A}$ beneath the ocean is much more variable than its common representation.

Beneath Layer $2 \mathrm{~A}$ the best-fit structure matches the logged structure reasonably well. The best-fit structure approximates an averaged, simplified version of the profile obtained from logging. It demonstrates that if seismic data of sufficiently good quality are mapped into the domain of intercept time and ray parameter without substantial loss of data integrity, an inversion can be obtained that reveals a very detailed picture of Layer 2B/ $2 \mathrm{C}$ structure. This result is very encouraging. Bratt and Purdy (1984) have used traveltime and amplitude characteristics, including power-versus-range computations, 


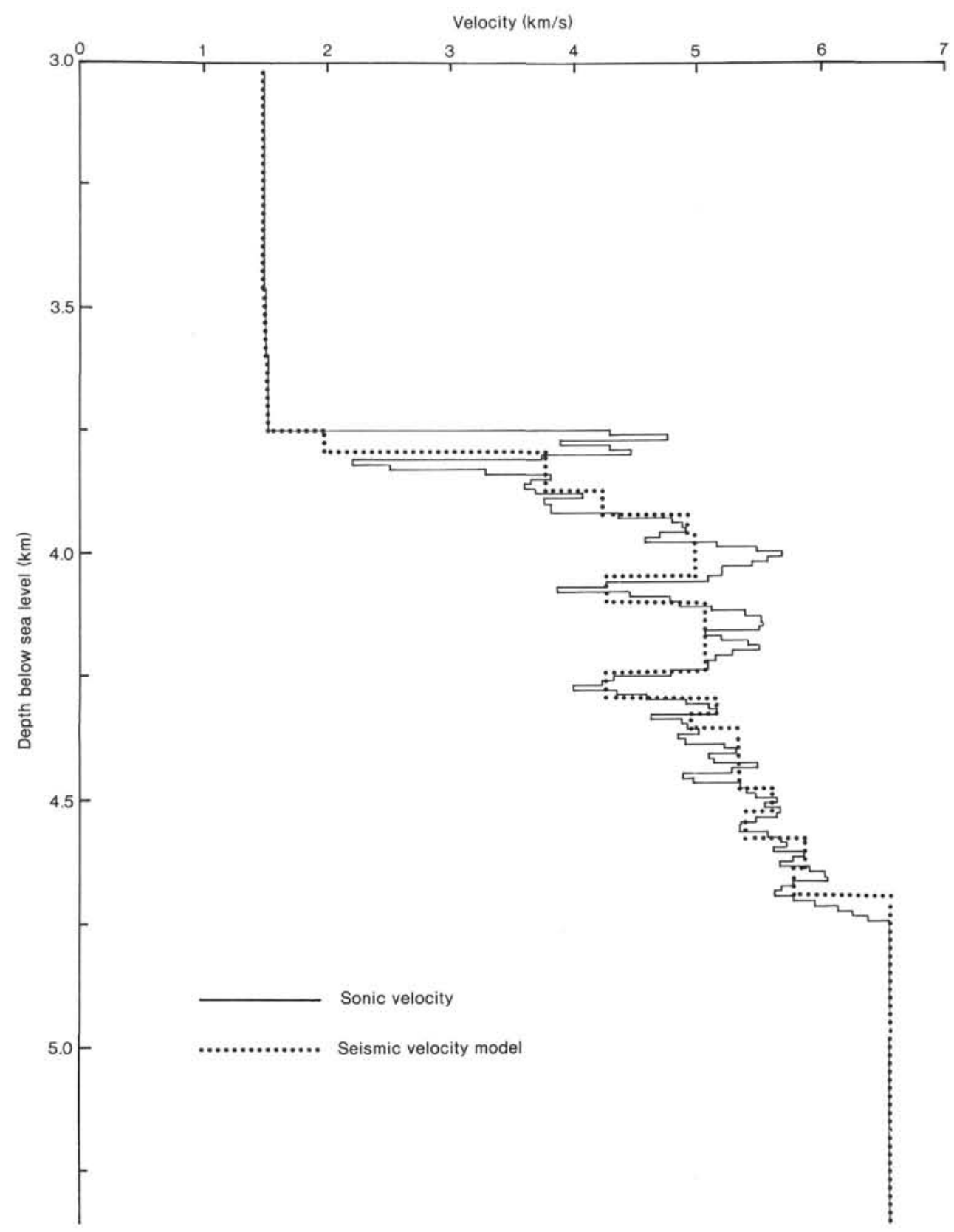

Figure 8. Comparison of the best-fit structure shown in Figure 6 to the velocity structure obtained by averaging the sonic logs (see text for discussion).

that show that Layer 2 structure is quite variable along a $500-\mathrm{km}$ line of ocean bottom seismometer (OBS) deployments at the $0.5-\mathrm{m}$.y. isochron parallel to the East Pacific Rise at around $13^{\circ} \mathrm{N}$. Their study suggests that the total thickness of Layer 2 varies up to $700 \mathrm{~m}$, and they find that, in places, there is no evidence of Layer 2B. They base the latter finding largely on the absence of a peak in the first-arrival power at ranges of 5 to $10 \mathrm{~km}$, and not on variations in structure as derived from traveltime inversions. Our analysis demonstrates that we could derive information about the details of structure directly from traveltime inversions, and this would greatly augment any interpretation based on peaks in the first arrival power.

\section{APPLICABILITY OF SYNTHETIC SEISMOGRAMS}

The extent to which synthetic seismogram modeling can be used to analyze data recorded under field conditions depends, in part, on how far the idealizations that go into the computation of synthetics depart from real conditions. Certainly the synthetic source, a unit impulse, is very different from the sound sources that can be deployed at sea. Practical sound sources normally have an extended pulse length that limits temporal resolution. As described above, the $\tau-p$ seismogram shows a welldefined primary branch of postcritical energy that breaks away from the quarter-ellipse defining the arrival re- 
flected from the sediment/basement interface at $p=$ $264 \mathrm{~ms} / \mathrm{km}$ (Figs. 1 and 4). However, between $p=264$ $\mathrm{ms} / \mathrm{km}$ and $p=198 \mathrm{~ms} / \mathrm{km}$, where the discontinuity in the primary branch occurs, the time separation of postcritical energy and precritical energy from the sediment/basement reflector is always less than about $75 \mathrm{~ms}$. In practice, the separation of these two arrivals might not be perceived. The two arrivals would most likely merge and interfere, and not be recognized as separate events. Furthermore, the postcritical branch does not correspond to first arrivals in $X-T$; its resolution relies on its coherence and the ability of the $\tau-p$ mapping scheme to record arrivals buried within a background of precritical reflections from the sedimentary section and upper basement. Real data may well display a primary branch with a highest resolvable slowness that corresponds to that of the reflector that first emerges (the reflector that emerges before the seafloor reflection) and/ or that point where the primary branch becomes well separated from the precritical reflections. The net result would be that the inversion would yield a greater velocity for the uppermost crust than is actually present. In fact, Stephen (1983) and Stephen and Harding (1983) interpret a velocity of $4.6 \mathrm{~km} / \mathrm{s}$, or $217 \mathrm{~ms} / \mathrm{km}$, for the uppermost crust on the basis of inversion studies of an oblique seismic experiment (OSE) performed in Hole 504B that included downhole instrument recordings. Our synthetics are not appropriate for comparison with such an experimental configuration. It seems possible that the OSE seismograms simply lacked sufficient resolution to detect the thin low-velocity part of the upper crust.

Another important limitation on the application of synthetic seismogram studies is the inherent assumption of laterally homogenous plane layers, a situation that is probably met rarely, if ever, in reality. Synthetic seismograms that include two-dimensional structure (i.e., lateral variability) can be computed, but the degree of twodimensionality must be known in advance. The effects of lateral variability will depend upon the nature of the variations. For instance, layers may maintain their average velocity but vary randomly in thickness, or conversely, they may vary in velocity but not in thickness. In general, one might expect both thickness and velocity to vary simultaneously. One simple effect of lateral variations would be the introduction of random temporal fluctuations in all arrivals, and these fluctuations would introduce similar fluctuations in the $\tau-p$ representation of the data. These fluctuations would lead to a much greater degree of raggedness in the first-pass $\tau$-sum inversion. An interpreter would probably smooth out most of these variations by either picking an averaged $\tau, p$ primary branch or eliminating extraneous layers in the inverted structure. Whether low-velocity zones would remain detectable would depend entirely on the relative magnitude of the variations produced by the low-velocity zones with respect to the magnitude of the changes introduced by the lateral variations and cannot be predicted in advance.

Both of the above types of limitations have the effect of making real seismic data generally less capable of detailed resolution than synthetic data, and so real data translate into more poorly resolved velocity profiles. How- ever, highly impulsive sounds like those produced by modern water guns permit the high temporal resolution needed for the derivation of detailed velocity profiles. The arrivals that define LVZ 1 , for instance, have ray paths less than $10 \mathrm{~km}$ long. If the upper kilometer of the crust is studied with high-energy water gun experiments, we might therefore hope to obtain information on structural variability on a scale of a few tens of meters vertically and $10 \mathrm{~km}$ or so laterally, a substantial improvement on conventional techniques.

\section{CONCLUDING REMARKS}

Downhole sonic logging at DSDP Hole 504B provided in situ compressional- and shear-wave velocity profiles together with density logs that allow the computation of full elastic synthetic seismograms. The log data show that the structure in oceanic Layer 2 can be readily resolved into its three components $(2 \mathrm{~A}, 2 \mathrm{~B}, 2 \mathrm{C})$, each of which has a distinct profile. The presence in Layers $2 \mathrm{~A}$ and $2 \mathrm{~B}$ of prominent low-velocity zones motivated us to compute synthetics in the domain of intercept time and ray parameter $(\tau-p)$, where these effects have a diagnostic signature. The basic findings are from this study of Hole 504B are as follows.

1. Downhole logging indicates that Layer $2 \mathrm{~A}$ has a very variable velocity profile, but this variable velocity structure could not be recognized in the $\tau-p$ synthetic.

2. A discontinuity occurs in the primary branch of postcritical energy in the $\tau-p$ synthetic that can be recognized as the response to the low-velocity zones in Layer $2 \mathrm{~B}$, even though these zones are very small and the synthetic is computed for a $10-$ to $30-\mathrm{Hz}$ bandwidth.

3. A simplified traveltime inversion of the synthetic data based on the $\tau$-sum method, in which negative-thickness excursions were interpreted as being the result of low-velocity intervals, yielded a structure that recovered much of the detailed structure identified by logging in Layers $2 \mathrm{~B}$ and $2 \mathrm{C}$.

4. The analysis leads us to believe that if seismic measurements characterized by high signal-to-noise ratio and high temporal resolution could be mapped into the domain of intercept time and ray parameter without significant loss of integrity (as is possible with expanded spread profiles [ESPs] and computerized mapping), a careful analysis of the data could permit much more detailed velocity structures in oceanic Layers $2 \mathrm{~B}$ and $2 \mathrm{C}$ to be derived than is usually thought possible. The development of detailed velocity structures appears to be feasible even with the use of a strongly band-limited, though otherwise idealized, seismic source.

\section{ACKNOWLEDGMENTS}

We would like to thank the officers, crew and scientific party of the Glomar Challenger Leg 83, without whose diligence and hard work the well logs could not have been completed. Peter Buhl and Tom Brocher participated in several valuable discussions regarding this project. We would particularly like to thank Joyce Alsop, who revised the software; without her help the synthetics might not have been completed. Virginia Rippon did much of the drafting for this manuscript. Dennis Hayes, Greg Mountain, and two anonymous reviewers greatly improved the content of this paper. This work was partly supported by National Science Foundation grant OCE 81-10919 and Office of Naval Research contract TO-0098, scope HH. 


\section{REFERENCES}

Aki, K., and Richards, P. G., 1980. Quantitative Seismology, Theory and Methods: San Francisco (W. H. Freeman and Co.).

Anderson, R. N., Honnorez, J., Becker, K., Adamson, A. C., Alt, J. C., Emmermann, R., Kempton, P. D., Kinoshita, H., Laverne, C., Mottl, M. J., and Newmark, R. L., 1982. DSDP Hole 504B, the first reference section over $1 \mathrm{~km}$ through Layer 2 of the oceanic crust. Nature (London), 300:589-594.

Anderson, R. N., O'Malley, H., and Newmark, R. L., 1985. Use of geophysical logs for quantitative determination of fracturing, alteration, and lithostratigraphy in the upper oceanic crust, Deep Sea Drilling Project, Holes 504B and 556. In Anderson, R. N., Honnorez, J., Becker, K., et al., Init Repts DSDP, 83: Washington (U.S. Govt. Printing Office), 443-478.

Becker, K., Von Herzen, R. P., Francis, R. J. G., Anderson, R. N., Honnorez, J., Adamson, A. C., Alt., J. C., Emmermann, R., Kempton, P. D., Kinoshita, H., Laverne, C., Mottl, M., and Newmark, R. L., 1982. In situ electrical resistivity and bulk porosity of the oceanic crust, Costa Rica Rift. Nature (London), 300:594-598.

Bratt, S. R., and Purdy, G. M., 1984. Structure and variability of oceanic crust on the flanks of the East Pacific Rise between $11^{\circ}$ and $13^{\circ}$ N. J. Geophys. Res., 89:6111-6125.

Cann, J. R., Langseth, M. G., Honnorez, J., Von Herzen, R. P., White, S. M., et al., 1983. Init. Repts DSDP, 69: Washington (U.S. Govt. Printing Office).

Dedman, E. V., Lindsey, J. P., and Schramm, M. W., Jr., 1975. Stratigraphic modelling: a step beyond bright spot. World Oil, 180(6): 61-65.

Diebold, J. B., and Stoffa, P. L., 1981. The traveltime equation, tau-p mapping, and inversion of common midpoint data. Geophysics, 46(3):238-254.

McMechan, G. A., and Ottolini, R., 1980. Direct observation of a p- $\tau$ curve in the slant stacked wave field. Bull. Seismol. Soc. Am., 70(3):775-789.
Moos, D., and Zoback, M. D., 1983. In situ studies of velocity in fractured crystalline rocks. J. Geophys. Res., 88:2345-2358.

Newmark, R. L., Anderson, R. N., Moos, D., and Zoback, M. D., 1985. Sonic and ultrasonic logging of Hole 504B and its implications for the structure, porosity, and stress regime of the upper 1 $\mathrm{km}$ of the oceanic crust. In Anderson, R. N., Honnorez, J., Becker, K., et al., Init. Repts DSDP, 83: Washington (U.S. Govt. Printing Office), 479-510.

Phinney, R. A., Roy Chaudhury, K., and Frazer, N. L., 1981. Transformation and analysis of record sections. J. Geophys. Res., 86: 359-377.

Sheriff, R. E., 1977. Limitations on resolution of seismic reflections and geologic detail derivable from them. In Payton, C. E. (Ed.), Seismic Stratigraphy-Applications to Hydrocarbon Exploration. Mem. Am Assoc. Pet. Geol., 26:3-14.

Stephen, R. A., 1983. The oblique seismic experiment on Deep Sea Drilling Project Leg 70. In Cann, J. R., Langseth, M. G., Honnorez, J., Von Herzen, R. P., White, S. M., et al., Init. Repts. DSDP, 69: Washington (U.S. Govt. Printing Office), 301-308.

Stephen, R. A., and Harding, A. J., 1983. Travel time analysis of borehole seismic data. J. Geophys. Res., 88:8289-8298.

Stoffa, P. L., and Buhl, P., 1979. Two-ship multichannel seismic experiments for deep crustal studies. J. Geophys. Res., 84:7645-7660.

Stoffa, P. L., Buhl, P., Diebold, J. B., and Wenzel, F., 1981. Direct mapping of seismic data to the domain of intercept time and ray parameter: a plane wave decomposition. Geophysics, 46(3):255-267.

Wenzel, R., Stoffa, P. L., and Buhl, P., 1982. Seismic modelling in the domain of intercept time and ray parameter. IEEE Trans. Acoustics, Speech, Signal Process., 30(3):406-422.

Date of Initial Receipt: 25 July 1984

Date of Acceptance: 31 December 1984 